\title{
ESTUDO DOS PARAMÊTROS FÍSICO-QUÍMICOS, QUALIDADE DA ÁGUA E TROFIA DO RESERVATÓRIO DA USINA HIDRELÉTRICA DE SÁ CARVALHO, MINAS GERAIS, BRASIL
}

\section{STUDY OF PHYSICO-CHEMICAL, WATER QUALITY AND PLANT TANK TROPHIC OAK SA DAM, MINAS GERAIS, BRAZIL}

\author{
Marluce Teixeira Andrade Queiroz ${ }^{1}$; Carolina Andrade Queiroz ${ }^{2}$; Felipe Andrade Queiroz ${ }^{3}$; Millor \\ Godoy Sabará $^{4}$; Monica Maria Diniz Leão ${ }^{5}$; Camila Costa Amorim ${ }^{6}$ \\ ${ }^{1}$ Centro Universitário do Leste de Minas Gerais - UNILESTE - Coronel Fabriciano/MG - Brasil \\ marluce.queiroz@bol.com.br \\ ${ }^{2}$ Instituto Nacional de Seguridade Social - Rio de Janeiro/RJ - Brasil \\ carolanq@yahoo.com.br \\ ${ }^{3}$ Centro Universitário do Leste de Minas Gerais - UNILESTE - Coronel Fabriciano/MG - Brasil \\ felipeandradeq@yahoo.com.br \\ ${ }^{4}$ Universidade Estadual de Minas Gerais - UEMG- Belo Horizonte/MG - Brasil \\ mgsabara@hotmail.com.br \\ ${ }^{5}$ Universidade Federal de Minas Gerais - UFMG- Belo Horizonte/MG - Brasil \\ monicaleao@desa.ufmg.com.br \\ ${ }^{6}$ Universidade Federal de Minas Gerais - UFMG- Belo Horizonte/MG - Brasil \\ camilaamorim@desa.ufmg.com.br
}

\begin{abstract}
Resumo
O estudo se refere ao diagnóstico da influência quanto ao uso e ocupação do solo na qualidade da água do reservatório da UHE - Sá Carvalho, Antônio Dias, Minas Gerais (Brasil). Foram selecionados cinco pontos de amostragens diferenciados quanto à profundidade sendo apurados os parâmetros físico-químicos: temperatura da água, oxigênio dissolvido, condutividade elétrica, $p H$, turbidez, sólidos totais, sólidos totais dissolvidos, sólidos suspensos totais provenientes dos relatórios da CEMIG. Os resultados de qualidade da água foram divididos para o período de estiagem (agosto/2014) e chuvoso (novembro/2014) e, de maneira geral, apresentaram variação sazonal.Constatou-se que no período com maior precipitação pluviométrica parâmetros como turbidez e sólidos suspensos totais foram maiores, enquanto na estação seca, e à medida que se adentrava no reservatório (montante para jusante) indicadores físico-químicos como condutividade elétrica foram mais elevados. Com base nos achados, subsídios básicos são apresentados para a tomada de decisões no que se refere às estratégias de planejamento e medidas conservacionistas da área do entorno do reservatório, dentre outros.
\end{abstract}

Palavras-chave: qualidade da água, reservatório hidrelétrico, rio Piracicaba, medidas mitigadoras.

\section{Introdução}


A geração de energia a partir da Usina Hidrelétrica (UHE) utiliza como matéria-prima principal um recurso renovável, mas ambientalmente vulnerável, que é a água fluvial, se qualificando como opção menos impactante para o ambiente, em especial para a atmosfera, pela baixa relação $\left[\mathrm{CO}_{2}\right] \mathrm{W}^{-1}$ em comparação com uso de combustível fóssil e mais seguro que a energia nuclear. Outros aspectos positivos importantes relacionados com a construção de reservatórios são: a regularização da hidrologia dos rios, minimizando riscos de enchentes e vazões muito baixas, favorecendo a implantação de corredores hidroviários e de projetos de irrigação. Além disso, identifica-se o uso múltiplo dos recursos hídricos, tais como, esporte e turismo (TUNDISI et al. 2010).

Contudo, a eletricidade oriunda do barramento implica em impactos ambientais negativos nas dimensões ecológicas e sociais, exigindo a adoção de medidas mitigadoras (ALBUQUERQUE FILHO, 2002). As distorções estão presentes em todas as fases dos projetos hidroelétricos. Dentre eles, são mais conhecidos à inundação de áreas de flora nativa, terras cultiváveis e patrimônio histórico e cultural, além do deslocamento de populações. Os efeitos cumulativos destas atividades resultam em alterações significativas, não somente nas características físicas dos corredores dos rios, mas também nos ecossistemas fluviais. Dentre as alterações das características ecológicas (interações entre a biota e o ambiente aquático), destacam-se alteração nos parâmetros físicoquímicos; elevação nos teores de metais pesados; perda de habitat; erosão; decaimento nos valores recreativos e estéticos do rio (FERNANDES et al., 2014). Além disso, os ecossistemas fluviais barrados e usados para geração de energia elétrica são afetados tanto a jusante, quanto a montante das barragens e com reflexos em toda a bacia de captação (ALBUQUERQUE FILHO et al., 2010).

O paradoxo é que as mesmas forças que promovem a crescente demanda energética, principalmente a necessidade do aumento da oferta de energia para processos produtivos, demandam a proteção da qualidade e quantidade de água em ambientes fluviais, pois, não existe nenhuma forma de produção que dispense o uso de água doce em pelo menos uma etapa de seu processo. Granjeiroet al. (2014) alerta quanto à relevância de diagnóstico dos fatores que afetam a qualidade da água, bem como prognósticos dos impactos futuros decorrentes da probabilidade de determinados eventos ou condições específicas, para melhor auxiliar a administração dos recursos hídricos com ações concretas e eficientes.

Nessa perspectiva, a proposta desse estudo consistiu no diagnóstico espacial e temporal das condições parâmetros-chave de qualidade da água fluvial no reservatório da UHE - Sá Carvalho localizado em Antônio Dias, rio Piracicaba, Bacia Hidrográfica do Rio Doce (BHRD), Minas Gerais, Brasil. Nesse estudo, os achados físico-químicos oriundos dos relatórios da CEMIG (2014) foram utilizados na construção do Índice de Qualidade da Água para Reservatório (IQAR) 
conforme proposto pelo Instituto Ambiental do Paraná para verificar a degradação da qualidade da água nesses compartimentos aquáticos.

O trabalho busca contribuir para o melhor conhecimento dos aspectos ecológicos do rio Piraciba relacionados principalmente com o aproveitamento de seu potencial hidroelétrico, se inserindo na premissa que o melhor conhecimento da magnitude e grandeza das perturbações ambientais é condição básica para busca do aproveitamento sustentável dos recursos hídricos, na perspectiva da bacia hidrográfica.

\section{Fundamentação Teórica}

\section{1 Índice de qualidade da água em reservatórios}

O Índice de Qualidade de Água em Reservatórios (IQAR) foi criado pelo Instituto Ambiental do Paraná (IAP) para verificar a degradação da qualidade da água dos reservatórios. Em atendimento a essa metodologia foi desenvolvida uma matriz que apresenta seis classes de qualidade da água, as quais foram estabelecidas a partir do cálculo dos percentis 10\%, 25\%, 50\%, $75 \%$ e $90 \%$ de cada uma das variáveis selecionadas conforme Tabela 1.

Tabela 1 - Classes de Qualidade x Variáveis do Reservatório

\begin{tabular}{|c|c|c|c|c|c|c|}
\hline \multicolumn{7}{|c|}{ Classes de qualidade (q) } \\
\hline Variáveis & 1 & 2 & 3 & 4 & 5 & 6 \\
\hline Déficit de Oxigênio Dissolvido (\%) & $\leq 5$ & $6-20$ & $21-35$ & $36-50$ & $51-70$ & $>70$ \\
\hline Clorofila $\mathrm{a}(\mu \mathrm{g} / \mathrm{L})$ & $\leq 1,5$ & $1,5-3,0$ & $3,1-5,0$ & $5,1-10$ & $11-32$ & $>32$ \\
\hline Fósforo total (Pmg/L) & $\leq 0,01$ & $0,011-0,025$ & $0,026-0,040$ & $\begin{array}{l}0,041- \\
0,085\end{array}$ & $0,086-0,21$ & $>0,21$ \\
\hline Profundidade - Disco de Secchi (m) & $\geq 3$ & $3-2,3$ & $2,2-1,2$ & $1,1-0,6$ & $0,5-0,3$ & $<0,3$ \\
\hline $\begin{array}{l}\text { Demanda Química de Oxigênio } \\
\left(\mathrm{O}_{2} \mathrm{mg} / \mathrm{L}\right)\end{array}$ & $\leq 3$ & $3-5$ & $6-8$ & $9-14$ & $15-30$ & $>30$ \\
\hline Tempo de residência (dias) & $\leq 10$ & $11-40$ & $41-120$ & $\begin{array}{l}121- \\
365\end{array}$ & $366-550$ & $>550$ \\
\hline $\begin{array}{l}\text { Nitrogênio inorgânico Total } \\
(\mathrm{Nmg} / \mathrm{L})\end{array}$ & $\leq 0,15$ & $0,16-0,25$ & $0,26-0,60$ & $\begin{array}{l}0,61- \\
2,00\end{array}$ & $2,00-5,00$ & $>5,00$ \\
\hline $\begin{array}{l}\text { Cianobactérias } \\
\text { célulasx } 103 / \mathrm{mL})\end{array} \quad\left(\mathrm{n}^{\circ}\right.$ & $<1$ & $1,001-5$ & $5,001-20$ & $\begin{array}{l}20,001- \\
50\end{array}$ & $50,001-100$ & $>100$ \\
\hline Profundidade média (metros) & $\geq 35$ & $34-15$ & $14-7$ & $6-3,1$ & $3-1,1$ & $<1$ \\
\hline
\end{tabular}

Fonte: IAP (2015)

As variáveis relacionadas: Déficit de Oxigênio Dissolvido $(\%)^{1}$, Clorofila a $(\mu \mathrm{g} / \mathrm{L})$, Fósforo total $\left(\mathrm{PO}_{2}-\mathrm{mg} / \mathrm{L}\right)^{2}$, Profundidade Secchi $(\mathrm{m})$, Demanda Química de Oxigênio - DQO (mg/L) ${ }^{2}$, Tempo de residência (dias), Nitrogênio inorgânico total $(\mathrm{N}-\mathrm{mg} / \mathrm{L})^{2}$, Cianobactérias $\left(\mathrm{n}^{0}\right.$ de células $/ \mathrm{mL})^{3}$, Profundidade média (metros) que recebem peso (w) em função do seu nível de importância para avaliação da qualidade da água do reservatório conforme apresentado na Tabela 2.

Tabela 2 - Parâmetros de Qualidade da Água conforme IAP 


$\begin{array}{cc}\text { Clorofila a }(\mu \mathrm{g} / \mathrm{L}) & 15 \\ \text { Fósforo total }\left(\mathrm{PO}_{2}-\mathrm{mg} / \mathrm{L}\right)^{2} & 12 \\ \text { Profundidade } \mathrm{Secchi}(\mathrm{m}) & 12 \\ \text { Demanda química de oxigênio - DQO }(\mathrm{mg} / \mathrm{L})^{2} & 12 \\ \text { Tempo de residência }(\mathrm{dias}) & 10 \\ \text { Nitrogênio inorgânico total }(\mathrm{N}-\mathrm{mg} / \mathrm{L})^{2} & 8 \\ \text { Cianobactérias }\left(\mathrm{n}^{\mathbf{0}} \text { de células } / \mathrm{mL}\right)^{3} & 8 \\ \text { Profundidade média (metros) } & 6\end{array}$

15
12
12
12
10
8
8
6

Obs.: (1) média da coluna d'água; (2) média das profundidades I e II; e (3) concentração da profundidade média. Fonte: IAP(2015)

O IQAR deve ser calculado de acordo com a expressão:

IQAR: $\sum$ (wi.qi)/ $\sum w i$ (Equação 1)

Sendo: wi = peso da variável i;

qi = classe de qualidade em relação a variável i (pode variar de 1 a 6).

Os valores do IQAR são relativos a seis classes de qualidade da água entre não impactados à extremamente poluído representando o estado de degradação conforme apresentado na Tabela 3.

Tabela 3 - Valor do IQAR X Qualificação

\begin{tabular}{ccc|}
\hline Classe & Valor do IQAR & Qualificação \\
\hline I & $0-1,50$ & Não impactado ou muito pouco degradado \\
II & $1,51-2,50$ & Pouco degradado \\
III & $2,51-3,50$ & Moderadamente degradado \\
IV & $3,51-4,50$ & Criticamente degradado a poluído \\
V & $4,51-5,50$ & Muito poluído \\
VI & $>5,51$ & Extremamente poluído \\
\hline
\end{tabular}

Fonte: IAP (2015)

Em cada classe o IQAR se refere às condições que norteiam o uso do corpo aquático. Nessa perspectiva, a Classe I representa aos reservatórios não impactados ou muito pouco degradados. Nessa condiçãoidentifica-seboa saturação de oxigênio, concentração de matéria orgânica muito baixa, baixa concentração de nutrientes, alta transparência das águas, densidade de algas muito baixa, normalmente com pequeno tempo de residência das águas e/ou grande profundidade média. A Classe II representa um reservatório em condição de pouca degradação, corpos de água com pequeno aporte de nutrientes orgânicos e inorgânicos e matéria orgânica, pequena depleção de oxigênio dissolvido, transparência das águas relativamente alta, baixa densidade de algas, normalmente com pequeno tempo de residência das águas e/ou grande profundidade média; Classe III se refere ao moderadamente degradado e apresentando um déficit considerável de oxigênio dissolvido na coluna d' água podendo ocorrer anoxia na camada de água próxima ao fundo em determinados períodos, com médio aporte de nutrientes e matéria orgânica, grande variedade e densidade de algumas espécies de algas, sendo que algumas espécies podem ser predominantes. Nessa condição existe uma tendência moderada a eutrofização e o tempo de residência das águas bastante considerável. As piores situações se referem às Classes IV, V e VI.

Para a Classe IV o reservatório se encontra criticamente degradado a poluído; são verificadas entradas de matéria orgânica capazes de produzirem uma depleção crítica nos teores de 
oxigênio dissolvido da coluna d'água, aportes consideráveis de cargas de nutrientes, alta tendência a eutrofização, ocasionalmente com desenvolvimento maciço de populações de algas e/ou cianobactérias, ocorrência de reciclagem de nutrientes, baixa transparência das águas associada principalmente a alta turbidez biogênica. A partir desta Classe é possível a ocorrência de mortandade de peixes em determinados períodos de acentuado déficit de oxigênio dissolvido.

A Classe V se relaciona com corpo hídrico muito poluído, com altas concentrações de matéria orgânica, geralmente com supersaturação de oxigênio dissolvido na camada superficial e baixa saturação na camada de fundo. Grande aporte e alta reciclagem de nutrientes. Corpos de água eutrofizados, com florações de algas e/ou cianobactérias que freqüentemente cobrem grandes extensões da superfície da água, o que limita a sua transparência. Retratado a condição de reservatório extremamente poluído se encontra a Classe VI. Trata-se dos corpos de água com condições bióticas seriamente restritas, resultante de severa poluição por matéria orgânica ou outras substâncias consumidoras de oxigênio dissolvido. Ocasionalmente ocorrem processos de anoxia em toda a coluna de água. Aporte e reciclagem de nutrientes muito altos. Corpos de água hipereutróficos, com intensas florações de algas e/ou cianobactérias cobrindo todo o espelho d'água. Eventual presença de substâncias tóxicas.

Em reservatórios, o cálculo do IET a partir dos valores de fósforo conforme:

IET = 10. (6-(1,77-0,42x $(\operatorname{lnPT}) / \ln 2))($ Equação 2$)$

Sendo fósforo total (PT) é expresso em $\mu \mathrm{g} / \mathrm{L}$.

Os valores do IET são classificados segundo classes de estado tróficos, apresentadas na Tabela 4, juntamente com suas características.

Tabela 4 - Valor do IET X Qualificação para reservatórios

\begin{tabular}{|c|c|c|}
\hline Estado Trófico & IET & Qualificação \\
\hline Ultraoligotrófico & $\mathrm{IET} \leq 47$ & Produtividade muito baixa ou insignificante \\
\hline Oligotrófico & $47<\mathrm{IET} \leq 52$ & Produtividade baixa e não ocorrem interferências indesejáveis de nutrientes \\
\hline Mesotrófico & $52<$ IET $\leq 59$ & Produtividade intermediária com possíveis implicações no IQA \\
\hline Eutrófico & $59<$ IET $\leq 63$ & Alta produtividade, redução da transparência, impactado \\
\hline Supereutrófico & $63<$ IET $\leq 67$ & Alta produtividade, baixa transparência, florações de algas \\
\hline Hipereutrófico & IET $>67$ & Alta produtividade, florações de algas e mortandade de peixes \\
\hline \multicolumn{3}{|c|}{ Fonte: CETESB (2007); LAMPARELLI (2004) } \\
\hline \multicolumn{3}{|c|}{ Nesse contexto, a mensuração do IQAR permite relacionar os diversos mecanismos c } \\
\hline \multicolumn{3}{|c|}{ sistema hídrico com a bacia de drenagem. A sua aplicação ao reservatório da UHE - Sá Carvalh } \\
\hline \multicolumn{3}{|c|}{ buscou determinar em particular a qualidade das águas e estabelecer prognósticos visando à } \\
\hline
\end{tabular}

\section{Metodologia}




\section{1 Área de estudo}

A UHE - Sá Carvalho faz parte do planejamento pertinente ao desenvolvimento do sistema energético integrado regional afetando portando o ciclo hidrológico da BHRP com repercussões socioeconômicas consideráveis para a região (ELS et al., 2012).

A hidrelétrica localizada no município de Antônio Dias, Minas Gerais, teve o início de sua construção em 1947 e culminando com sua operaçãodesde 1951. O comprimento da barragem alcança112 m e 34 m respectivamente em Antônio Dias e Severo, enquanto a altura máxima se mostra bastante próxima nas duas localidades, sendo $15 \mathrm{~m}$ e $14 \mathrm{~m}$ respectivamente, integrando a cadeia de reservatórios existente na BHRD. O volume do reservatório corresponde apenas a $1,38 \mathrm{hm}^{3}$ (Antônio Dias), quatro unidades geradoras e potência instalada de $78 \mathrm{MW}$ tornando a UHE - Sá Carvalho um dos quatros maiores da região da BHRD - MG (CEMIG, 2015).

O município de Antônio Dias apresenta relevo predominante montanhoso correspondente à cerca de $70 \%$ da sua extensão territorial. A construção da UHE - Sá Carvalho implicou em significativa perda de solo agravada pelo extrativismo mineral (ouro), pecuária e exploração florestal. A principal formação florestal se constitui em bioma devastado e ameaçado. Trata-se da Mata Atlântica cobertura vegetal que atua como elemento responsável pela estruturação do solo através do sistema radicular que se constitui em defesa eficiente contra a ação da água. Entretanto, se observa o aumento excessivo em resposta à exacerbação da erosão laminar conhecida pela retirada das camadas mais finas do solo, implicando também no incremento da densidade das raízes. Nota-se em pontos com maior declividade a erosão em sulco em função da ausência da cobertura vegetal explicitando a existência com pontos de menor desgaste (RODRIGUES et al., 2007). O bioma sido alvo da megassivicultura com taxa de desmatamento da ordem de $457 \mathrm{Km}^{2} /$ ano, sendo a vegetação remanescente em torno de $22,25 \%$ sendo fator coadjuvante preponderante em relação aos efeitos sinérgicos e cumulativos provenientes do aproveitamento hidroelétrico (NOGUEIRA et al., 2015).

A condição trófica da BHRP, ou seja, a carga dos nutrientes detectada foi prejudicada através da decomposição do material vegetal após o enchimento do reservatório. A partir da estabilização do sistema, essa condição passou a ocupar posição secundária. Para o sistema consolidado, a contribuição de cada tributário passa a ser ainda mais destacada. Trata-se de corpos d'água distintos que recebem influência ininterrupta da bacia de formação e ocupação do solo (agropecuária, indústrias, densidade demográfica, conservação das margens e pluviometria) agregando valores aos seus parâmetros físico-químicos afetando desse modo a qualidade da água superficial e subterrânea (ELS, 2014). 
A profundidade do reservatório da UHE - Sá Carvalho foi afetada em função da vazão média afluente e volume de sedimento retido. Os sedimentos são provenientes da precariedade das práticas conservacionistas pertinentes ao solo. As técnicas de cultivo ainda fazem uso das queimadas principalmente entre produtores com menor poder aquisitivo. A coivara elimina nutrientes essenciais para plantas, tais como, fósforo, nitrogênio e potássio, contribuindo para o esgotamento do solo e extermínio de grandes áreas nativas. Vale destacar que atualmente a agricultura apresenta uma participação na economia nacional da ordem de $26,5 \%$, colocando o País em posição evidenciada como exportador ao nível da realidade global (TIBA et al., 2014).Além disso, a eficiência energética, em torno de $95 \%$, depende da série de vazões naturais e da vazão média de longo termo,relacionadas com os índices pluviométricos na região. As principais características do reservatório são apresentadas na Tabela 5.

Tabela 5 - Características do reservatório da UHE- Sá Carvalho

\begin{tabular}{ccc}
\hline Parâmetros Técnicos & Antônio Dias & Severo \\
\hline Nível máximotopo da comporta & $373,03 \mathrm{~m}$ & $370,5 \mathrm{~m}$ \\
Nível máximo normal & $372,93 \mathrm{~m}$ & $369,50 \mathrm{~m}$ \\
Nível mínimo operativo & $371,43 \mathrm{~m}$ & $366,00 \mathrm{~m}$ \\
Cota da soleira da comporta & $375 \mathrm{~m}^{-}$ & $371,35 \mathrm{~m}$ \\
Volume de reservaçãono nível máximo & $1,80 \mathrm{hm}^{3}$ & $0,098 \mathrm{hm}^{3}$ \\
Volume de reservação no nível normal & $1,73 \mathrm{hm}^{3}$ & $0,0793 \mathrm{hm}^{3}$ \\
Volume mínimo operativo & $0,77 \mathrm{hm}^{3}$ & $0,0326 \mathrm{hm}^{3}$ \\
Volume útil & $0,96 \mathrm{hm}^{3}$ & $0,0467 \mathrm{hm}^{3}$ \\
\end{tabular}

Fonte: ANEEL, 2014

\subsection{Monitoramento}

Para o reservatório da UHE - Sá Carvalho os pontos de monitoramento foram selecionados representando os diferentes usos nasmargens do reservatório e também o início, meio do reservatório e final. O estudo abrangeutreze pontos distintos (Tabela 6), sendo ambiente lótico e dez deles localizados no Rio Piracicaba, MG. Os resultados relativos aos indicadores físico-químicos foram oriundos dos relatórios da CEMIG em campanhas realizadas em agosto (estação seca) e 
novembro (estação chuvosa) em 2014. Além disso, a concessionária de energia também disponibilizou os dados relativos à precipitação pluviométrica no reservatório e nível do lago.

Tabela 6 - Estações de monitoramento da qualidade da água noreservatório da UHE - Sá Carvalho

\begin{tabular}{|c|c|c|c|}
\hline Estação & Descrição & Curso d'água* & Coordenadas \\
\hline SC-LI 01 & $\begin{array}{l}\text { Montante do reservatório Antônio } \\
\text { Dias, no início domesmo. Localizado } \\
\text { em área urbana, próximo a ponte } \\
\text { central da cidade. }\end{array}$ & Rio Piracicaba** & $\begin{array}{l}19^{\circ} 39^{\prime} 48.60 ” \mathrm{~S} \\
42^{\circ} 52^{\prime} 46.00^{\prime \prime} \mathrm{O}\end{array}$ \\
\hline $\begin{array}{l}\text { SC-LI 02-S } \\
\text { SC-LI 02-ZF }\end{array}$ & $\begin{array}{l}\text { Reservatório Antônio Dias a cerca de } \\
500 \mathrm{~m} \text { do barramento localizado em } \\
\text { área urbana }\end{array}$ & Rio Piracicaba** & 19³8’39.70”S \\
\hline \multicolumn{4}{|l|}{ SC-LI 02-F } \\
\hline SC-LI 03-S & $\begin{array}{l}\text { Reservatório Severo a cerca de } 300 \mathrm{~m} \\
\text { do barramento }\end{array}$ & Ribeirão Severo** & $19^{\circ} 38^{\prime} 15.40^{\prime \prime} \mathrm{S}$ \\
\hline SC-LI 03-ZF & & & $49^{\circ} 22^{\prime} 60^{\prime \prime} \mathrm{O}$ \\
\hline \multicolumn{4}{|l|}{ SC-LI03-F } \\
\hline SC-LI 04-S & $\begin{array}{l}\text { Trecho de vazão reduzida à montante } \\
\text { da casa de força }\end{array}$ & Rio Piracicaba** & $19^{\circ} 38^{\prime} 11.30^{\prime \prime} \mathrm{S}$ \\
\hline SC-LI 04-ZF & & & $48^{\circ} 18^{\prime} 60^{\prime \prime} \mathrm{O}$ \\
\hline \multicolumn{4}{|l|}{ SC-LI 04-F } \\
\hline SC-LI $05-S$ & Jusante da casa de força & Rio Piracicaba** & $19^{\circ} 38^{\prime} 2.20^{\prime \prime} \mathrm{S}$ \\
\hline SC-LI 05-ZF & & & $42^{\circ} 48^{\prime} 19.80 ” O$ \\
\hline SC-LI 05-F & & & \\
\hline
\end{tabular}

\section{Resultados e discussão}

\subsection{Precipitação pluviométrica e nível do reservatório}

Na Tabela 7 são apresentados os dados de precipitação pluviométrica e nível do reservatório em agosto e novembro/2014. Vale destacar, a regulação do lago ocorre através da abertura das comportas para conter as cheias, portanto não são identificadas variações superiores a $1 \%$, sendo preservadas as condições para operação normal do empreendimento hidrelétrico garantindo o fornecimento normal para usuários do sistema. 
Tabela 7 - Pluviometria e nível do lago da UHE - Sá Carvalho

\begin{tabular}{cccc}
\hline Mês & Precipitação $(\mathbf{m m})$ & Nível do lago (m) $^{\mathbf{1}}$ & Nível do lago (m) $^{\mathbf{2}}$ \\
\hline Agosto/2014 & 175 & 372,15 & 366,87 \\
\hline Novembro/2014 & 208 & 372,98 & 368,79
\end{tabular}

${ }^{1}$ Barragem em Antônio Dias

${ }^{2}$ Barragem em Severo

Fonte: CEMIG, 2015

\subsection{Qualidade da água no reservatório}

O IQAR (Figura 1) refletiu impactos relativos às alterações provenientes da urbanização (densidade demográfica, dinâmica da produção, o consumo de água e produção de esgoto) nas áreas no entorno da UHE - Sá Carvalho. Destaca-se a interferência da industrialização relacionada com a exploração de minério de ferro, que apresenta impactos potenciais importantes sobre a qualidade de água, seja pela possibilidade de aumento de sólidos suspensos, seja pela alteração química da água nas lagoas de decantação utilizadas no beneficiamento do minério (ZIMMERMANN et al., 2008).Os valores mensurados para o IQAR se situaram ente 2,51 até 3,50 sendo o corpo hídrico classificado como moderadamente degradado. A deterioração do IQAR pode estar associada aos índices de DQO.

Figura 1 - IQAR da UHE - Sá Carvalho

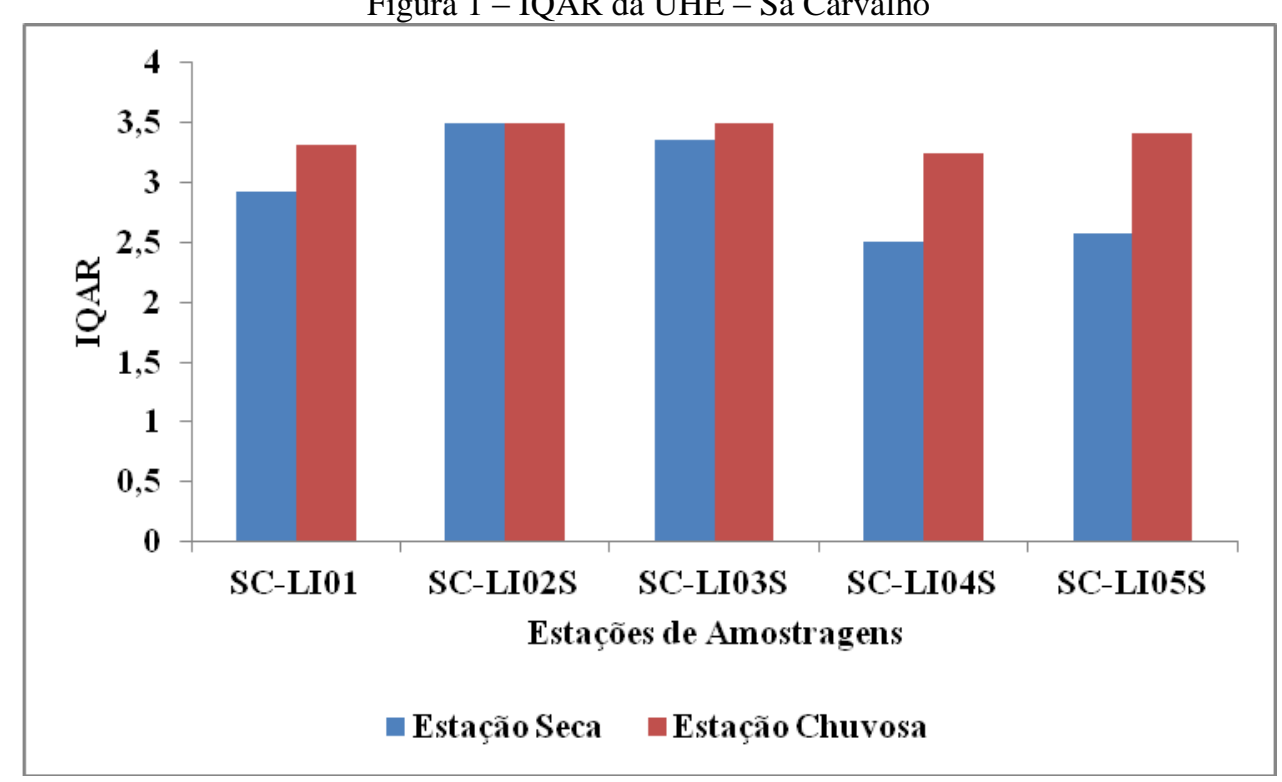

O aumento da concentração de DQO num corpo d'água deve-se principalmente a despejos de origem industrial. Os teores detectados na estação chuvosa em SC-LI02S e SC-LI03 correspondentes respectivamente à $40 \mathrm{mgO}_{2} / \mathrm{L}$ e $18 \mathrm{mgO}_{2} / \mathrm{L}$ (Tabela 8 ), sugerem a existência de 
substâncias tóxicas para as bactérias decompositoras relacionadas com o arraste decorrente do incremento da pluviometria.

Tabela 8 - DQO no reservatório da UHE - Sá Carvalho.

\begin{tabular}{ccc}
\hline DQO $\left(\mathbf{m g O}_{2} / \mathbf{L}\right)$ & Agosto/2014 & Novembro/2014 \\
\hline SC-LI01 & $<26$ & $<26$ \\
SC-L02S & $<26$ & 40 \\
SC-LI03S & 18 & $<26$ \\
SC-LI04S & $<26$ & $<26$ \\
SC-LI04S & $<26$ & $<26$ \\
\hline
\end{tabular}

Fonte: CEMIG (2014)

A temperatura da água (Figura 2) no reservatório na estação seca variou entre $18,0^{\circ} \mathrm{C}$ até $22,4^{\circ} \mathrm{C}$, enquanto na estação chuvosa foram detectados valores mais elevados entre $25,3^{\circ} \mathrm{C}$ até $30,0^{\circ} \mathrm{C}$ indicando relação com o comportamento térmico do Rio Piracicaba, MG, Brasil.

Figura 2 - Temperatura da água no reservatório da UHE - Sá Carvalho

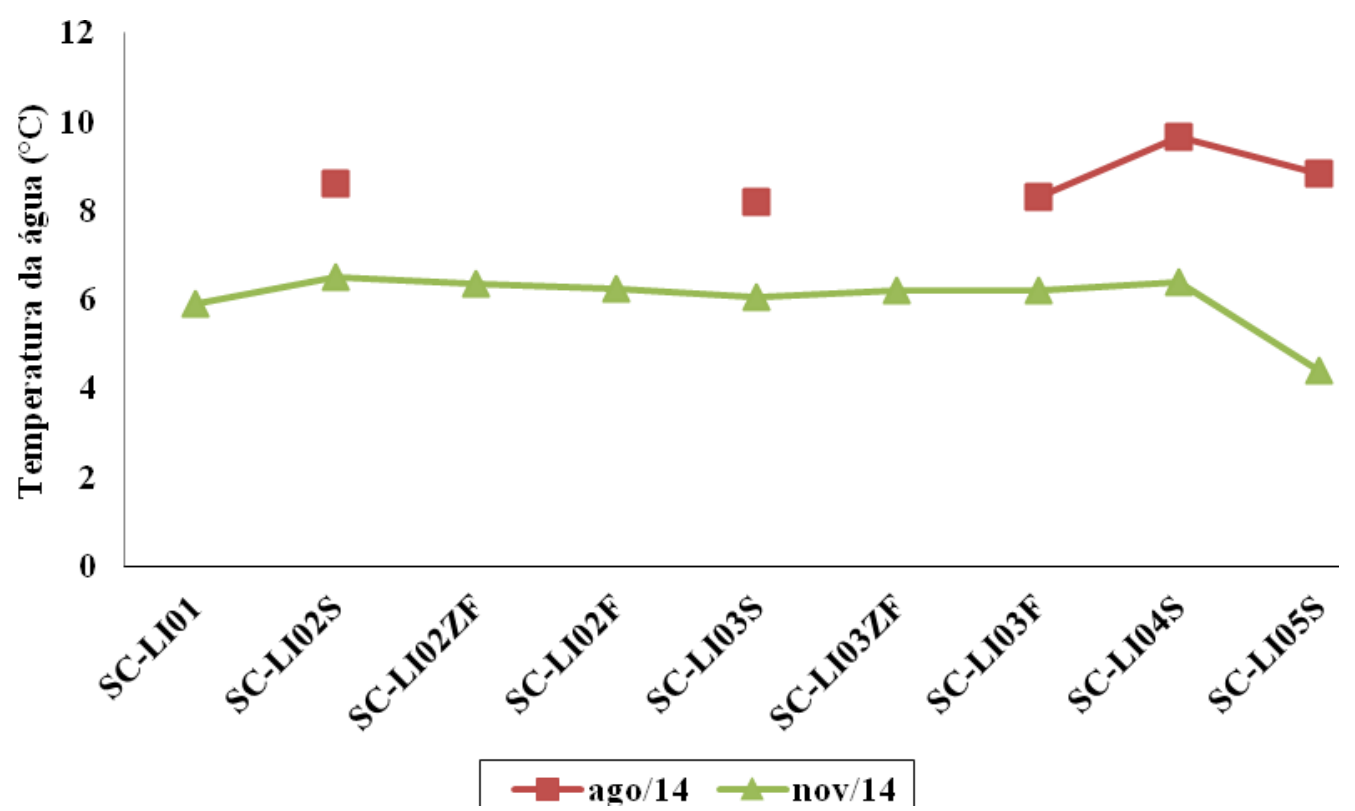

Queiroz (2006) identificou valores de temperatura da água para o Rio Piracicaba, abaixo de $20^{\circ} \mathrm{C}$ na estação seca indicando relação com a zona ripária proporcionando efetiva proteção. Entretanto, a temperatura identificada no reservatório em SC-LI03S foi mais baixa sendo $18^{\circ} \mathrm{C}$.Tal 
condição mostrou relação com o fenômeno típico associado às massas de água represadas conforme observado por Mahunguana e Bravo (2015).

O oxigênio dissolvido (OD) apresentou variaçõessazonais bem marcadas entre os períodos de estiageme chuvoso (Figura 3). Na estiagem, as concentrações de OD são mais elevadas, com valores médios na superfíciepróximos a $10 \mathrm{mg} / \mathrm{L}$ (supersaturação) em SCLI04S e SCLI05S. Noperíodo chuvoso, mesmo na superfície, o OD chegoua cair atingindo 6,4mg/L em SCLI04S e até 4,4mg/L em SCLI05S (Figura 3). Entretanto, destaca-se que o aumento da pluviometria não implicou em variações significativas da superfície para o fundo do reservatório. Os achados de mostraram condições mais homogêneas quanto ao teor de oxigênio dissolvido. Os piores resultados na estação seca em locais mais profundas podem ser atribuídos ao crescente consumo na mineralização de detritos da biomassa algal morta decantante (KOENING et al., 2014).

Figura 3 - Teores do oxigênio dissolvido no reservatório da UHE - Sá Carvalho

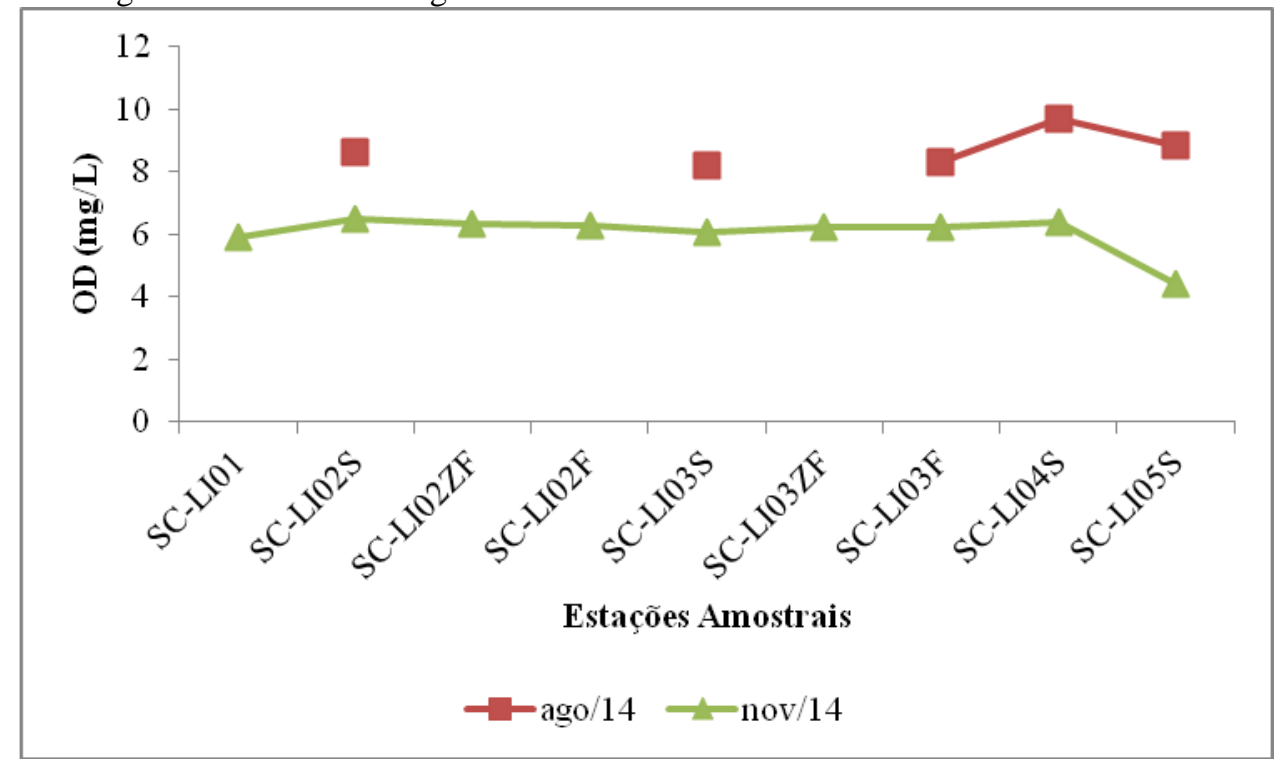

Tundisi (2000) pontua quanto à existência de outros fatores contributivos, tal como, a penetração da luz solar e proliferação de algas na superfície. Trata-se de condições preponderantes notadamente no período de estiagem quando o nível de reservatório se mostra mais profundo. Tratase de fenômeno típico em barramentos antigos que também foi observado neste reservatório, a proliferação da matéria algal absorve quase toda a luz incidente, deixando a camada inferior, o hipolimnio, sem luz para realizar fotossíntese. Mediante ausência ou diminuição acentuada da fotossíntese ocorre a decomposição de matéria orgânica no hipolimnio, principalmente das algas mortas que sedimentam a partir do epilimnio, consumindo o oxigênio da água, levando a condições anóxicas. Para corroborar esta hipótese se mostrou necessária a avaliação de mais parâmetros, como por exemplo, condutividade elétrica, $\mathrm{pH}$, fósforo, clorofila a e nitrogênio, dentre outros.

Em relação à condutividade elétrica foram detectados valores mais baixos na estação chuvosa (Figura 4), excetuando-se em SC-LI101 e SC-LI102 S que mostraram valores muito 
próximos independente das condições pluviométricas. No afluente ao reservatório em SC -LI03S foi verificada a maior amplitude de variação, sendo alcançado o valor correspondente a $105 \mu \mathrm{S} / \mathrm{cm}$ e $65 \mu \mathrm{S} / \mathrm{cm}$ respectivamente na estação seca e chuvosa. Constatou-se dependência com o volume das chuvas explicitando relação com a formação do solo. Esteves (1998) informa que em solos com predominância de rochas magmáticas tal como encontrado na UHE - Sá Carvalho a condutividade elétrica, em geral, se mostra determinada por produtos de intemperismo dessas formações. Nesse contexto, se verifica a importância do ciclo hidrológico para a qualidade da água também nesse quesito.

Figura 4 - Condutividade elétrica no reservatório da UHE - Sá Carvalho

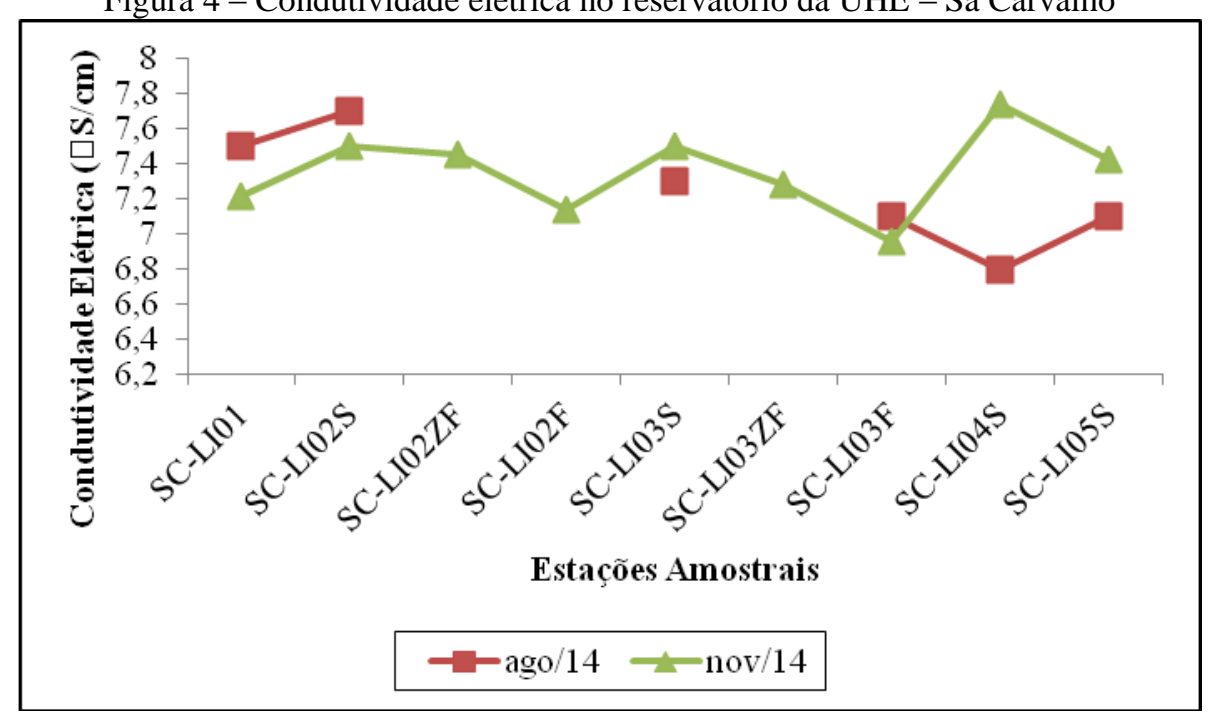

$\mathrm{O}$ pH nas águas do reservatório (Figura 5) se situou predominantemente acima de sete. Raras exceções foram detectadas em SC-LI03 F e SC-LI04S sendo respectivamente 6,96 (chuvas) e 6,8 (seca).De modo geral, nesse estudo, uma tendência de elevação do pH nos períodos chuvosos. A variação do $\mathrm{pH}$ associada às diferenças quanto ao nível das profundidades das estações amostrais não foram tão nítidas em função da sazonalidade. Entretanto, destaca-se o pH 7,74 mensurado em SC LI 04 S na estação chuvosa época em que o reservatório estava mais cheio. 


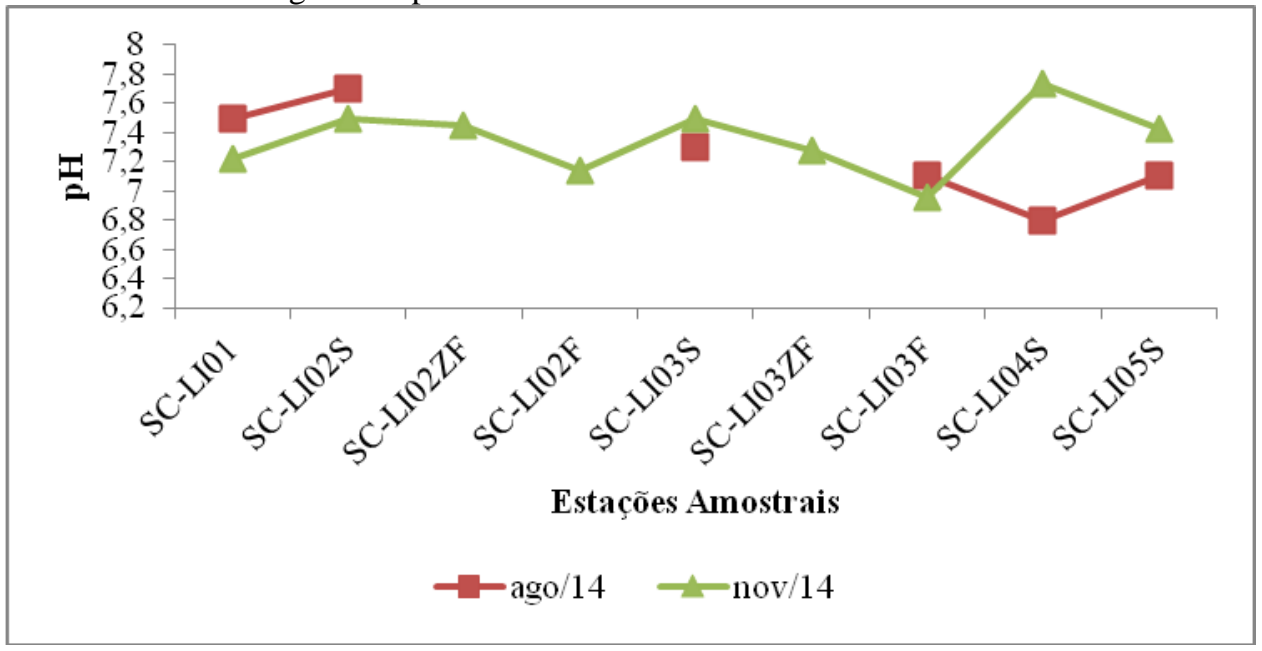

Os teores de fósforo total nas águas do reservatório (Figura 6) mostraram valores mais elevados na estação chuvosa sendo encontrado o valor máximo correspondente a $0,07 \mathrm{mg} / \mathrm{L}$ em SC - LI05S explicitando relação com os usos comprometedores capazes de afetar o sistema aquático. Destaca-se a concordância com o limite CONAMA 357/2005 e Deliberação Normativa COPAM/CERH-MG 01/2008 correspondente à 0,03mgP/L em ambientes lênticos.

Figura 6 - Fósforo total no reservatório da UHE - Sá Carvalho

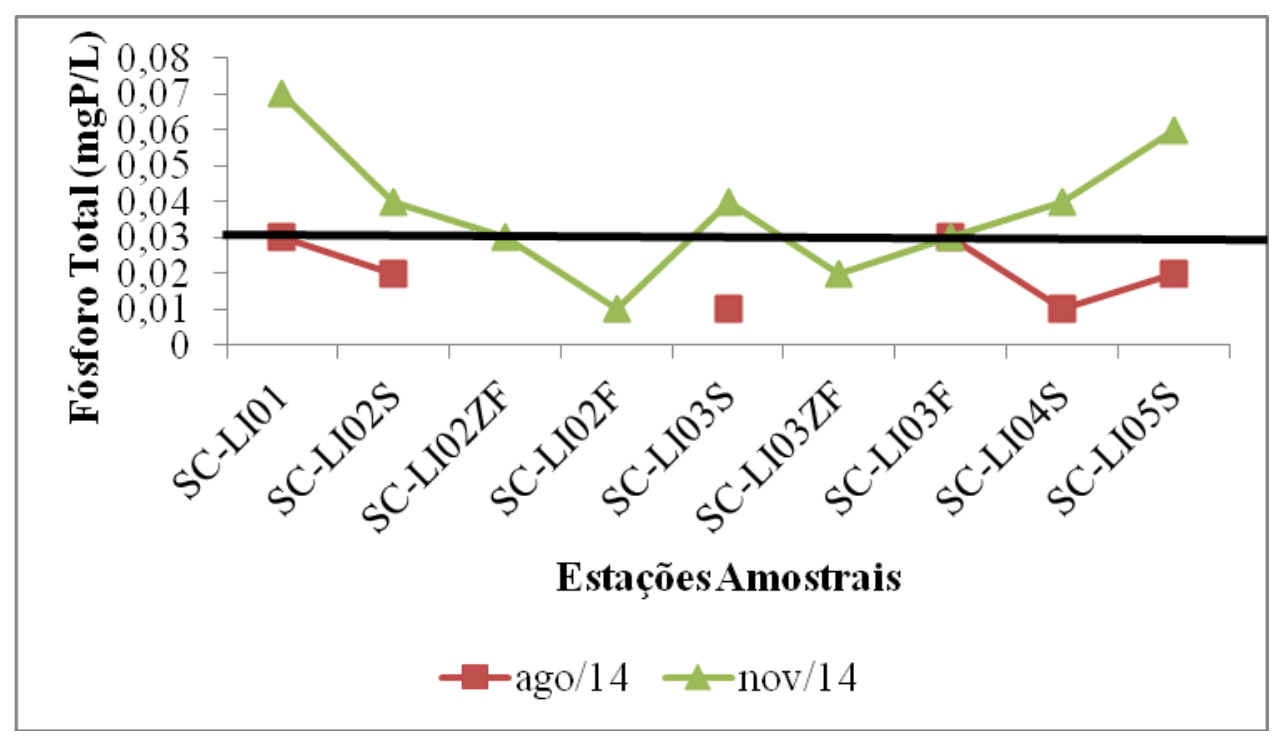

Assim como observado no IQAR, os valores do IET no período chuvoso (Figura 7) se apresentaram bastantes próximos em SC-LI101, SC-LI104S e SC-L105S correspondendo respectivamente a 44,81, 43,35 e 44,41, enquanto o valor mais elevado correspondeu a 50,49 em SC-LI02S. Em síntese o reservatório oscilou entre as condições ultraoligotrófico e oligotrófico apresentando baixa produtividade. 
Figura 7 - IET no reservatório da UHE - Sá Carvalho na estação chuvosa.

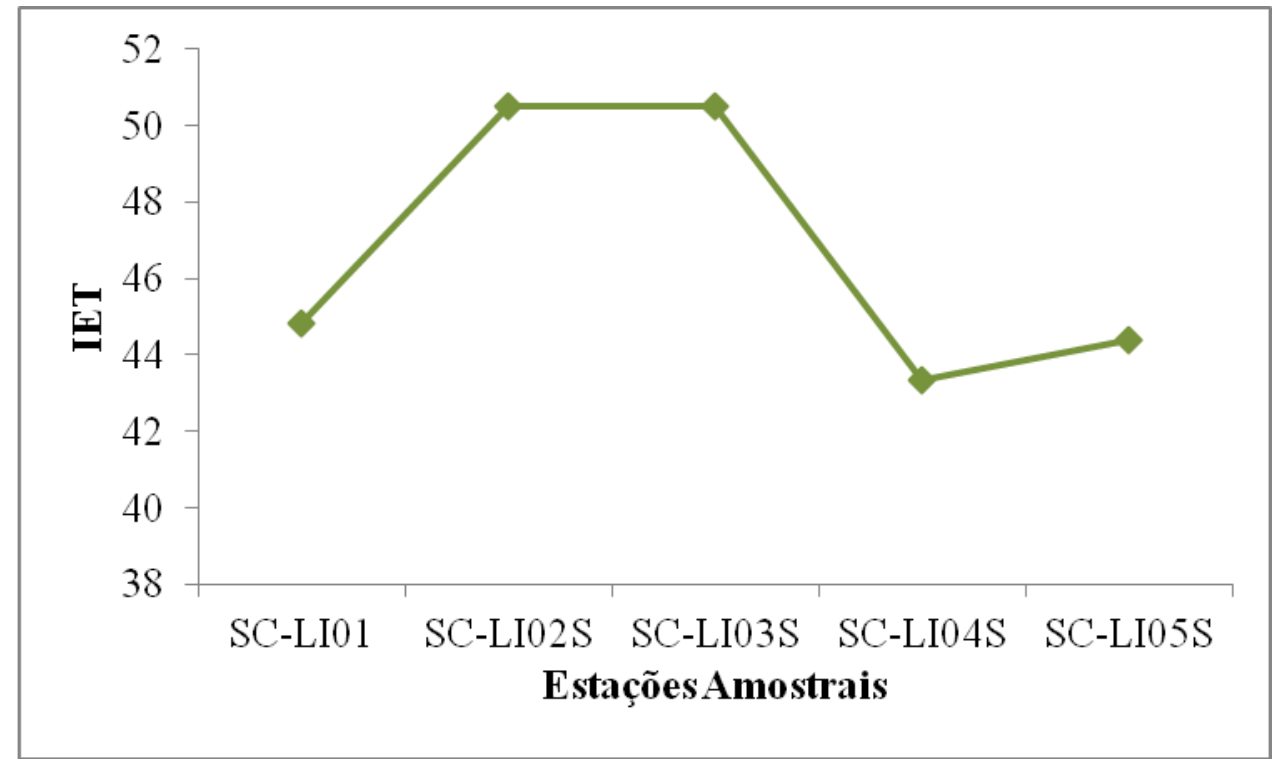

Em relação à clorofila a, Sólidos Dissolvidos Totais (SDT), Sólidos Suspensos Totais (SST), Sólidos Totais (ST),nitrogênio total e turbidez foram encontrados valores abaixo dos Valores Máximos Permitidos (VMP) do CONAMA 357/2005 e Deliberação Normativa COPAM/CERH-MG 1/2008 conforme apresentado na Tabela 9. 
Tabela 9 - Série de sólidos, nitrogênio total e turbidez no reservatório da UHE - Sá Carvalho

\section{Agosto}

\begin{tabular}{|c|c|c|c|c|c|c|}
\hline $\begin{array}{c}\text { Estação } \\
\text { Amostral }\end{array}$ & $\begin{array}{c}\text { Clorofila a } \\
\qquad(\mu \mathrm{g} / \mathrm{L})\end{array}$ & $\begin{array}{l}\text { SDT }^{*} \\
(\mathrm{mg} / \mathrm{L})\end{array}$ & $\begin{array}{l}\text { SST** } \\
(\mathrm{mg} / \mathrm{L})\end{array}$ & $\begin{array}{c}\mathrm{ST} \\
(\mathrm{mg} / \mathrm{L})\end{array}$ & $\begin{array}{c}\text { Turbidez } * * * \\
\text { (NTU) }\end{array}$ & $\mathbf{N}_{\text {Total }}(\mathrm{mg} / \mathrm{L})$ \\
\hline SC-LI01 & $<0,01$ & 54 & $<12$ & 59 & 3,1 & 0,8 \\
\hline SC-LI02S & $<0,01$ & 48 & $<12$ & 49 & 1,4 & 1,0 \\
\hline SC-LI02ZF & - & - & - & - & - & - \\
\hline SC-LI02F & - & - & - & - & - & - \\
\hline SC-LI03S & 18 & 67 & $<10$ & 67 & 1,7 & 1,3 \\
\hline SC-LI03ZF & - & - & - & - & - & - \\
\hline SC-LI03F & - & 58 & - & 62 & 1,5 & 1,2 \\
\hline SC-LI04S & 20,1 & 47 & $<12$ & 50 & 2,2 & 0,4 \\
\hline SC-LI05S & 16,9 & 54 & $<12$ & 57 & 1,6 & 0,9 \\
\hline
\end{tabular}

\section{Novembro}

\begin{tabular}{ccccccc}
\hline SC-LI01 & $<0,12$ & 42 & 15 & 57 & 21,2 & 0,6 \\
\hline SC-LI02S & $<0,12$ & 43 & $<2$ & 45 & 14,4 & 0,7 \\
\hline SC-LI02ZF & - & 57 & 4 & 61 & 15,1 & 0,8 \\
\hline SC-LI02F & - & 51,5 & $<2$ & 52 & 31,2 & 0,7 \\
\hline SC-LI03S & $<0,12$ & 40,5 & 2 & 42 & 14,1 & 0,8 \\
\hline SC-LI03ZF & - & 64 & $<2$ & 64 & 13,7 & 1,1 \\
\hline SC-LI03F & - & 44,5 & $<2$ & 45 & 14,4 & 0,7 \\
\hline SC-LI04S & $<0,12$ & 34 & 49 & 83 & 88,6 & 0,1 \\
\hline SC-LI05S & $<0,12$ & 43,5 & 17,5 & 61 & $\mathbf{1 0 0}$ & \\
\hline VMP* & $\mathbf{3 0}$ & $\mathbf{5 0 0}$ & $\mathbf{1 0 0}$ & - & & \\
\hline
\end{tabular}


Dentre os parâmetros físico-químicos (Tabela 9) se destaca a turbidez que demostrou, com maior nitidez, os impactos pertinentes à elevação da pluviometria. Além disso, refletiu as diferenças significativas com relação à profundidade. Exemplificando em SCL-I03ZF a turbidez atingiu 13,7NTU, enquanto em SC-LI04S apurou-se o valor de 88,6NTU.Todavia, ressalta-se que a turbidez inclui também partículas não sedimentáveis, como as algas e, metais como o ferro. Sabogal et al. (2011) destaca que a contaminação por metais na água, além de ocorrer a partir da liberação da água intersticial da coluna sedimentar, ocorre também a partir da ressuspensão de sedimentos contaminados.

No reservatório da UHE - Sá Carvalho foram identificados teores distintos dos metais ferro, manganês e potássio nas estações de amostragens na estação chuvosa (Tabela 10), explicitando os efeitos da pluviometria na carga de metais.

Tabela 10 - Teor de ferro, manganês e potássio no reservatório da UHE - Sá Carvalho.

Novembro/2014

\begin{tabular}{|c|c|c|c|c|}
\hline $\begin{array}{c}\text { Estação } \\
\text { Amostral }\end{array}$ & $\begin{array}{l}\text { Ferro dissolvido } \\
\qquad(\mathrm{mg} / \mathrm{L})\end{array}$ & $\begin{array}{l}\text { Ferro total } \\
\qquad(\mathrm{mg} / \mathrm{L})\end{array}$ & $\begin{array}{c}\text { Manganês dissolvido } \\
\text { (mg/L) }\end{array}$ & $\begin{array}{l}\text { Potássio total } \\
\text { (mg/L) }\end{array}$ \\
\hline SC-LI01 & $<0,10$ & 0,23 & $<0,04$ & 1,36 \\
\hline SC-LI02S & $<0,10$ & 0,21 & $<0,04$ & 1,43 \\
\hline SC-LI02ZF & - & - & - & - \\
\hline SC-LI02F & - & - & - & - \\
\hline SC-LI03S & 0,07 & 0,25 & $<0,03$ & 1,47 \\
\hline SC-LI03ZF & - & - & - & - \\
\hline SC-LI03F & - & - & - & 1,17 \\
\hline SC-LI04S & 0,18 & 0,36 & $<0,04$ & - \\
\hline SC-LI05S & $<0,10$ & 0,24 & $<0,04$ & 1,46 \\
\hline VMP* & $\mathbf{0 , 3 0}$ & - & - & - \\
\hline
\end{tabular}

Os resultados mostraram que os teores de ferro dissolvido foram inferiores ao VMP estabelecido no CONAMA 357/2005 e COPAM/CERH-MG 01/2008. Em relação ao ferro total foram detectados valores maiores em SC-LI03S e SC-LI04S sendo respectivamente 0,25 e 0,36 mg/L. Os teores de manganês dissolvido foram em todas as estações de amostragens inferiores 
a 0,04ppm. Entre os metais mensurados o potássio total alcançou as maiores concentrações variando entre um mínimo de 1,17mg/L em SCLI03F e máximo de 1,47mg/L em SC-LI03S. As concentrações mensuradas dos metaisexplicitou as condições geológicas favoráveis da BHRP que se caracteriza pela sua elevada capacidade de resistência mecânica, ficando normalmente preservada nas frações mais grosseiras do solo, justificando-se pela resistência daquelas formações rochosas aos mecanismos físico-químicos, derivados da biogeocenose (SANTOS et al., 2014).

\section{Conclusão}

Na realidade, o conjunto dos dados dos parâmetros físico-químicos do reservatório da UHE - Sá Carvalho mostra sua capacidade de absorver os aportes externos provenientes da BHRP. Verificou-se que o barramento hidrelétrico embora esteja com mais de sessenta anos de funcionamento se apresenta moderadamente degradado conforme a mensuração do IQAR. Além disso, a qualidade da água apresenta condições favoráveis, tal como, valores elevados do oxigênio dissolvidos, $\mathrm{pH}$ em torno da neutralidade e teores de metais dissolvidos inferiores ao limites estabelecidos no CONAMA 357/2005. Tal condição, mostra sua resiliência físico-quimica frente à ação impactante dos agentes ambientais.

Entretanto, se destaca a importância do desenvolvimento das ações capazes de contribuir para a preservação ecológica do reservatório. Dentre essas, um dos aspectos se relaciona com a eutrofização que demanda o controle das atividades desenvolvidas na sua bacia de drenagem. Incluindo-se ai efetivação fiscalização quanto ao despejo dos efluentes industriais mediante programa de monitoramento abrangente e eficaz. Além disso, reforça-se a necessidade da implantação do sistema de tratamento dos esgotos sanitários em todos os municípios da BHRP.

Aspectos ecológicos relevantes foram constatados denotando a importância do reservatório para a comunidade. Entretanto, considerando as questões pertinentes ao crescimento populacional e demanda energética se mostra importante repensar às condições capazes de aperfeiçoar o melhor aproveitamento da água estocada, aumento do tempo útil da represa favorecido por uma melhor distribuição de sedimentos, controle da erosão e poluição. Entende-se que as atividades de pesca devem ser fomentadas mediante a introdução de alevinos visando o repovoamento das águas represadas e educação ambiental continuada direcionada para as comunidades que convivem com o empreendimento.

\section{Abstract}

The study relates to the diagnosis of influence on the use and occupation of land in the water quality of the hydroelectric plant's reservoir (UHE) Sa - Carvalho, Antonio Dias, Minas Gerais (Brazil). 
Five points of different samples were selected as the depth being calculated physicochemical parameters: water temperature, dissolved oxygen, conductivity, $\mathrm{pH}$, turbidity, total solids, total dissolved solids, total suspended solids of CEMIG reports. The results of water quality were divided into the dry season (August / 2014) and rainy (November / 2014) and, in general, showed up sazonal.Constatou-variation in the period with the highest rainfall rainfall parameters such as turbidity and solids total suspended were higher, while in the dry season, and as they entered through the reservoir (upstream to downstream) physico-chemical indicators such as electrical conductivity were higher. Based on the findings, basic subsidies are given for making decisions with regard to planning strategies and conservation measures around the reservoir area, among others.

Key-words: water quality, hydroelectric reservoir, Piracicaba river, mitigating measures.

\section{Referências}

ALBUQUERQUE FILHO, J. L.; SAAD, A. R.; ALVARENGA, M. C.. Considerações acerca dos impactos ambientais decorrentes da implantação de reservatórios hidrelétricos com ênfase nos efeitos concorrentes em aquíferos livres e suas consequências. Geociênc. (São Paulo), São Paulo, v. 29, n. 3, 2010.

APHA, AWWA, WEF. Standard methods for the examination of water and wastewater. 18th ed. Washington, DC: 1998.

CETESB (2007). Relatório de qualidade das águas interiores no Estado de São Paulo: 2006. São Paulo: CETESB, 2007. (Série Relatórios).

CEMIG. Relatório Final de Monitoramento da Qualidade da Água - UHE Sá Carvalho, 2014.

ESTEVES, F.A. 1998. Fundamentos de Limnologia. Interciência, Rio de Janeiro. 602 pp.

FERNANDES, C. C.; NOGUEIRA, A.; ALVES-GOMES, J. A.. A new genus and species of electric knife fish (Gymnotiformes: Hypopomidae, Microsternarchini) fromthe Negro River, South America. Proceedings of the Academy of Natural Sciences of Philadelphia, v. 163, p. 95-118, 2014.

GRANJEIRO, M. L.; SANTIAGO, M. M. F.; SILVA, C.M.S.V. ; MESQUITA, B. A.; FRISCHKORN, H. ; MENDES FILHO, J.. Factor Analysis in the Study of Geochemical Processes in the Apodi Sedimentary Basin. Revista Brasileira de Recursos Hídricos, v. 19, p. 115, 2014.

IAP - Instituto Ambiental do Paraná. Qualidade da água para reservatórios. 2000. Disponível: < http://www.iap.pr.gov.br/>, Acesso: junho/2015.

KOENING, M. L.;FLORES MONTES, M. J. ; LEÇA, EnideEskinazi ; Silva, A.S.X. . New record of kashiwo sanguinea (Dinophyta) in the tropical estuarine waters of Northeastern Brazil (Western Atlantic).BrazilianJournalofBiology (Impresso), v. 74, p. 191-198, 2014.

LAMPARELLI , M. C. Grau de trofia em corpos d'água do estado de São Paulo: avaliação dos métodos de monitoramento. São Paulo : USP/ Departamento de Ecologia., 2004. 235 f. Tese de doutorado, Universidade de São Paulo, 2004.

MAHUNGUANA, M. J. ; BRAVO, J. M.. Avaliação do efeito de critérios de projeto no dimensionamento de redes de macrodrenagem através da simulação hidrológico-hidráulica. Revista Brasileira de Recursos Hídricos, v. 20, p. 484495, 2015.

QUEIROZ, M. T. A.. Bioacumulação de metais pesados no Rio Piracicaba, Minas Gerais, aplicando a análise por ativação neutrônica instrumental. 2006. 92 f. Dissertação (Mestrado em Engenharia Industrial) - Centro Universitário do Leste de Minas Gerais, Coronel Fabriciano, 2006.

SABOGAL PAZ, L. P ; GandiniAyerbe, M. A . Technology selection for water drinking treatment how to take into account environmental aspects?.In: BILIBIO, Carolina, HENSEL, Oliver, SELBACH, J. Editora e co-editoras:

Fundação Universidade Federal do Pampa, Unikassel, PGCult/UFMA. (Org.).Sustainable water management in the 
tropics and subtropics - and case studies in Brazil.PGCult/UFMA: Fundação Universidade Federal do Pampa, Unikassel, PGCult/UFMA, 2011, v. Vol 4, p. 583-604.

SANTOS, W. J. R.; SILVA, B. M.; OLIVEIRA, G. C.; VOLPATO, M. M. L.; LIMA, J. M.; CURI, N.;MARQUES, J. J. Soilmoisture in the root zone and its relationtoplant vigor assessedbyremotesensingat management scale. Geoderma, v.221-222, p.91-95, 2014.

SIQUEIRA, L.F.S ; IBAÑEZ ROJAS, M. O. A. ; COSTA NETO, J.J.G . DETERMINAÇÃO ESPECTROMÉTRICA DE FERRO (II) PELO SISTEMA FE (II)/ KSCN EM ÁGUA DO MAR DA PRAIA DO CALHAU, SÃO LUIS, MARANHÃO (BRASIL). Acta Tecnológica, v. 6, p. 27-34, 2011.

TUNDISI, J. G Gerenciamento da qualidade da água de represas. Universidade Federal de São Carlos: ILEC; IIE, 2000, p. 280.

TUNDISI, J. G. ; MATSUMURA-TUNDISI, T ; Morais M A ; Pereira , K. C ; Luzia , A.P ; Passerini, M. G. ; Chiba W; SÉBASTIEN, N. Y. . Cold fronts and reservoirs limnology: an integrated approach towards the ecological dynamics of freshwater ecosystems. Brazilian Journal of Biology (Impresso), v. 70, p. 815-824, 2010.

\section{Dados dos autores:}

Nome completo: Prof. Mestre Marluce Teixeira Andrade Queiroz

Filiação Institucional: Centro Universitário do Leste de Minas Gerais, Departamento de Engenharia Sanitária e Ambiental.

Endereço: Bairro Universitário, Coronel Fabriciano, Minas Gerais, Brasil.

Telefone: (31)38465651

e-mail:marluce.queiroz@bol.com.br

Nome completo: Pesquisadora Carolina Andrade Queiroz

Filiação Institucional: Instituto Nacional de Seguridade Social

Endereço: Rio de Janeiro, Brasil

Telefone: (31)38231828

e-mail: carolanq@yahoo.com.br

Nome completo: Pesquisador Felipe Andrade Queiroz

Filiação Institucional: Centro Universitário do Leste de Minas Gerais, Departamento de Direito.

Endereço: Minas Gerais, Brasil

Telefone: (31)986281209

e-mail: felipeandradeq@yahoo.com.br

\section{Nome completo: Prof. Dr Millor Godoy Sabará}

Filiação Universidade Estadual de Minas Gerais, Departamento de Engenharia Ambiental Endereço: João Monlevade, Minas Gerais, Brasil 
Telefone: (31) 3916-0471

e-mail: mgsabara@hotmail.com.br

Nome completo: Prof. Dra. Monica Maria Diniz Leão

Filiação Universidade Federal de Minas Gerais, Departamento Saneamento Meio Ambiente e Recursos Hídricos.

Endereço: Belo Horizonte, Minas Gerais, Brasil.

Telefone: (31) 3409-1880

e-mail:monicaleao@desa.ufmg.com.br

Nome completo: Prof. Dra. Camila Costa Amorim

Filiação Universidade Federal de Minas Gerais, Departamento Saneamento Meio Ambiente e Recursos Hídricos.

Endereço: Belo Horizonte, Minas Gerais, Brasil.

Telefone: (31) 3409-1880

e-mail: camilaamorim@desa.ufmg.com.br

Submissão: 27/07/2015

Aceito: $14 / 09 / 2015$ 